\title{
Low-Dose Misoprostol versus Vaginal-Insert Dinoprostone for At-Term Labor Induction: A Prospective Cohort Study
}

\author{
Laura Emilia Muñoz Saá1*, María Dolores Martín Ríos², María Rosario Noguero Meseguer¹ \\ ${ }^{1}$ Department of Obstetrics and Gynecology, Rey Juan Carlos Hospital, Madrid, Spain \\ ${ }^{2}$ Department of Preventive Medicine, Rey Juan Carlos Hospital, Madrid, Spain \\ Email: *laura.munoz@hospitalreyjuancarlos.es, maria.mrios@hospitalreyjuancarlos.es, rosario.noguero@hospitalreyjuancarlos.es
}

How to cite this paper: Saá, L.E.M., Ríos, M.D.M. and Meseguer, M.R.N. (2017) LowDose Misoprostol versus Vaginal-Insert Dinoprostone for At-Term Labor Induction: A Prospective Cohort Study. Open Journal of Obstetrics and Gynecology, 7, 824-834. https://doi.org/10.4236/ojog.2017.78083

Received: June 30, 2017

Accepted: July 30, 2017

Published: August 2, 2017

Copyright $\odot 2017$ by authors and Scientific Research Publishing Inc. This work is licensed under the Creative Commons Attribution International License (CC BY 4.0).

http://creativecommons.org/licenses/by/4.0/

\begin{abstract}
Introduction: Given the pharmacological change taking place in Spanish delivery rooms, we designed this study to compare the effectiveness and safety of misoprostol $(25 \mathrm{mcg} / 4 \mathrm{~h})$ to $10 \mathrm{mg}$ dinoprostone in its slow-releasing vaginalinsert form to induce at-term labor. Methods: In a prospective cohort study (2013-2015), 401 at-term pregnant women referred for induction (Bishop score $\leq 6$ ), who gave birth at the Rey Juan Carlos Hospital in Móstoles (Madrid, Spain), of whom 241 participants were induced with misoprostol and 160 with dinoprostone. Patients were recruited by non-probabilistic sampling of consecutive cases as the inductions in the Obstetrics Block during the study period were indicated. Results: The cesarean section rate was $14 \%$ for the misoprostol group and $19 \%$ for the dinoprostone group [RR $=1.38$ (95\%CI: 0.89 - 2.13), $\mathrm{p}=0.145$ ]. No differences were found in the vaginal birth rate in $<24 \mathrm{~h}$ from starting induction [ $44 \%$ vs. $53 \%, \mathrm{RR}=1.08$ (0.90 - 1.29), $\mathrm{p}=0.401$ ], nor in the vaginal birth rate in $<12 \mathrm{~h}$, requiring oxytocin or meconium fluid, or for maternal-neonatal complications deriving from the method employed. The percentage of cesarean sections due to failed induction was lower in the misoprostol group ( $15 \%$ vs. $39 \%, \mathrm{p}=0.028)$. The time between induction and giving birth was shorter for the dinoprostone group ( $20 \mathrm{~h} \mathrm{vs.} 23.4 \mathrm{~h}, \mathrm{p}=0.018)$. Conclusion: Inducing delivery by low-dose misoprostol offers similar effectiveness and safety to induction by dinoprostone in its slow-releasing vaginal-insert form. However, our sample is limited, and few studies are available on the subject. Further analyses to draw solid conclusions are required.
\end{abstract}

\section{Keywords}

Labor Induction, Cervical Ripening, Misoprostol, Dinoprostone 


\section{Introduction}

In recent decades, the induced labor rate has substantially increased, has not always been considered duly justified and accounts for $20 \%-30 \%$ of all births [1] [2].

When cervical conditions are unfavorable, the most frequent form of inducing labor in our country is to administer intravaginal or intracervical prostaglandins [1]. Until recently, prostaglandin E2, or dinoprostone, has been the most widely used agent in our setting. However, it is an unstable product at room temperature, expensive and exclusively administered vaginally. Misoprostol, or prostaglandin E1, was originally registered to treat peptic ulcers, and has been explored as an agent to induce labor at different doses and posologies. Misoprostol is inexpensive, stable at room temperature and can be taken orally, vaginally or under the tongue. High drug doses and short intervals can trigger maternal-fetal complications, among which uterine hyperstimulation, both with and without altered fetal cardiotocographic registers, stand out which, at times, has led to is limited use. Over the years, different regimes have been explored to find the optimum dose [3].

Given the pharmacological change taking place in the clinical practice, the present study considers a comparative analysis between misoprostol and dinoprostone administered vaginally at the aforementioned doses to provide information about their effectiveness and safety for induced deliveries.

\section{Material and Methods}

A prospective cohort study was conducted during the period between 1 March 2013 and 24 May 2015 that compared the use of misoprostol and dinoprostone in pregnant women who had been induced at the Rey Juan Carlos Hospital in Móstoles (Madrid), Spain. This study included 401 at-term pregnant women who had been medically and obstetrically referred for induced delivery with unfavorable cervical conditions when induction commenced. Of the 401 patients, 241 were induced with misoprostol and 160 with dinoprostone. The inclusion criteria were: singleton pregnancies with live fetus, cephalic presentation at gestational age $\geq 37$ weeks, a Bishop score of $\leq 6$ at the start of induction, and no contraindications for vaginal birth or use of prostaglandins. The amniotic sac could be complete or ruptured, but with no sign of regular uterine dynamics. The exclusion criteria were background of cesarean section or other previous uterine surgery, gestational age $<37$ weeks, multiple pregnancies, intrauterine fetal death, women infected with human immunodeficiency virus (HIV), and pre-delivery evidence for compromised fetus as intrauterine growth restriction or nor reassuring fetal heart rate monitoring.

Patients were recruited by non-probabilistic sampling of consecutive cases as the inductions in the Obstetrics Block during the study period were indicated.

Following the protocol approved in our center, a check list was used prior to induction to evaluate maternal-fetal conditions and suitability of induction. The 
pregnant women with a Bishop score below or equal to 6 required a cervical maturity method. As both drugs are considered first-line drugs in this patient group that met the inclusion criteria, the research group offered the patient the chance to participate in the study and she received informed consent. After accepting and signing it, the obstetrician chose the cervical maturity method and followed our center's Induced Labor Protocol.

Low-dose misoprostol was used in this protocol $(25 \mathrm{mg} / 4 \mathrm{~h})$ for a maximum of $24 \mathrm{~h}$ (or six doses). Twenty-four hours after cervical maturity commenced, the patient was transferred to the Obstetrics Block if there was no sign of labor dynamics in order to be administered oxytocin intravenously $4 \mathrm{~h}$ after being administered the last drug.

When specialists opted for dinoprostone, it was used in its vaginal-insert slowreleasing form with $10 \mathrm{mg}$, maintained for a maximum 24-hour period, which was when patients were transferred to the Obstetrics Block. Thirty minutes after removing the device, oxytocin was intravenously administered in those patients who did not present regular uterine dynamics.

Any progress made in dilation and delivery, and any decisions about different interventions, e.g., amniotomy, use of analgesia, etc., were monitored according to the hospital's protocol.

In both cases, socio-demographic variables, pregnancy characteristics, data about induction, birth route and its temporal evolution were collected, along with data about puerperium, neonate characteristics and any maternal-fetal complications.

The study was approved by the Rey Juan Carlos Hospital Research Commission on 21 October 2016.

\section{Statistical analysis}

Sample size estimation was calculated with the result of a pilot study done with the first 50 patients, which evidenced a lower cesarean section rate, from $22 \%$ to $12 \%$, for induction with misoprostol. A statistical power of $80 \%$, a $95 \%$ confidence interval and a $5 \%$ percentage of losses were applied. The required sample size was 154 patients per treatment arm.

In the statistical analysis, the qualitative variables were presented in percentages, while the quantitative ones were presented as means and standard deviations (SD).

A chi-square test was used to evaluate the association between the qualitative variables. A student's $t$-test was used to compare the cervical maturity method with the quantitative variables.

The effect measure employed was relative risk (RR), and the difference of the means with their $95 \%$ CI.

Explanatory logistic regression modeling was used for the adjustments for all the possible confounder or interaction variables. The initial maximum model included all the variables that were statistically significant or clinically relevant in the univariate analysis.

A 0.05 level of significance was used to compare all the hypotheses. The statis- 
tical package employed was SPSS Windows 15.0.

\section{Results}

The two study groups, these being 160 pregnant women induced with dinoprostone $(40 \%)$ and 241 pregnant women induced with misoprostol (60\%), were homogeneous for maternal age, personal background and pregnancy characteristics, like gestational age, obstetric pathology throughout pregnancy and parity, and for cervical conditions when induction commenced (Table 1).

The reasons for induction in both study groups were premature membrane rupturing (37.9\%), chronologically prolonged pregnancy $(19 \%)$, gestational diabetes (13.4\%) and pregnancy-related hypertension (7\%). Some of the more

Table 1. Characteristics of the sample.

\begin{tabular}{|c|c|c|c|}
\hline Outcomes & $\begin{array}{c}\text { Misoprostol } \\
\text { N (\%) }\end{array}$ & $\begin{array}{c}\text { Dinoprostone } \\
\text { N (\%) }\end{array}$ & $\mathrm{p}$ \\
\hline \multicolumn{4}{|l|}{ Characteristics of the sample } \\
\hline Any personal background & $84(34.9)$ & $57(35.6)$ & 0.874 \\
\hline Obstetric pathology & $103(42.7)$ & $78(48.8)$ & 0.236 \\
\hline \multicolumn{4}{|l|}{ Parity } \\
\hline Nuliparous & $184(76.3)$ & $129(80.6)$ & 0.311 \\
\hline Multiparous & $57(23.7)$ & $31(19.4)$ & \\
\hline Maternal age ${ }^{*}$ & $32.1(4.8)$ & $31.7(5.5)$ & 0.456 \\
\hline Gestational age* & $40.1(1.3)$ & $39.8(1.3)$ & 0.011 \\
\hline \multicolumn{4}{|l|}{ Reasons for induction } \\
\hline Premature membrane rupturing (expectant management) & $85(35.3)$ & $27(16.9)$ & $<0.0001$ \\
\hline Chronologically prolonged pregnancy & $48(19.9)$ & $28(17.5)$ & 0.545 \\
\hline Pregnancy-related hypertension & $9(3.7)$ & $19(11.9)$ & 0.002 \\
\hline Insuline-dependent GD & $31(12.9)$ & $12(7.5)$ & 0.089 \\
\hline Non insuline-dependent GD & $11(4.6)$ & 0 & - \\
\hline Maternal decision & $4(1.7)$ & $4(2.5)$ & 0.556 \\
\hline Premature membrane rupturing (active management) & $23(9.5)$ & $17(10.6)$ & 0.723 \\
\hline Intrahepatic cholestasis of pregnancy & $4(1.7)$ & $9(5.6)$ & 0.028 \\
\hline Thrombophilia & $6(2.5)$ & $5(3.1)$ & 0.703 \\
\hline Oligoamnios & $7(2.9)$ & $12(7.5)$ & 0.034 \\
\hline Meconium fluid & $10(4.1)$ & $12(7.5)$ & 0.344 \\
\hline Macrosomia & $1(0.4)$ & 0 & \\
\hline Small fetus & $2(0.8)$ & $15(9.4)$ & $<0.0001$ \\
\hline \multicolumn{4}{|l|}{ Bishop score* } \\
\hline Initial bishop score ${ }^{\star}$ & $2.4(1.2)^{*}$ & $2.1(1.3)^{\star}$ & 0.059 \\
\hline Final bishop score & $6.6(2.3)^{*}$ & $6.1(2.7)^{*}$ & 0.051 \\
\hline
\end{tabular}

${ }^{*}$ Data are presented as $\bar{X} \quad(\mathrm{SD}) ;{ }^{* *} \mathrm{GD}$ (gestational diabetes). 
frequent reasons, like a ruptured sac and pregnancy-related hypertension, and other less frequent ones, like oligoamnios (4.7\%) and induction for small fetus for gestational age (4.2\%), were distributed differently between the study groups and were the object of the multivariable analysis (Table 1).

In the group in which cervical maturity was performed by vaginal misoprostol, two doses were necessary in $34 \%$ of the cases, and three doses in $25.7 \%$. The mean misoprostol dose was 2.2 tablets (Table 1 ).

Regarding evolution of cervical conditions after cervical maturity, a mean Bishop score of 6.6 was obtained for misoprostol, and one of 6.1 for dinoprostone, with a difference on the statistical significance limit $(p=0.051)$ (Table 1).

Oxytocin requirements, needing meconium fluid throughout induction and use of analgesia were similar for the treatment groups.

The cesarean section rate in the misoprostol-induced group was $14 \%$, and $19 \%$ in the dinoprostone group [RR $=1.38$ (95\%CI: $0.89-2.13), \mathrm{p}=0.145]$. Explanatory logistic regression modeling applied for the adjustments for the possible confounder variables and birth route did not differ according to the cervical maturity method used (Table 2). No differences were found in instrumental deliveries, position during the expulsive, episiotomies or tears according to the cervical maturity method employed, nor for the mean number of days hospitalized. There were more placental retention in the phase when the placenta was expelled in the vaginal deliveries in the dinoprostone-induced group (10.5\%) than in the misoprostol-induced group (4.3\%), $\mathrm{p}=0.02$.

Among the reasons for practicing a cesarean section, a lower percentage was found for failed induction in the misoprostol-induced group than for the dinoprostone-induced group ( $p=0.028$ ) (Table 2). No differences were found in the cesarean sections for delivery not progressing or for those practiced for risk of losing fetal well-being between both study groups.

The percentage of vaginal birth in less than $24 \mathrm{~h}$ from starting induction was $53 \%$ in the dinoprostone group and $44 \%$ for the misoprostol group. No significant differences were observed between the study groups after adjusting the confounder variables $[R R=1.08(0.90-1.29), p=0.401]$ (Table 2).

There were no differences in either the vaginal birth rate in less than $12 \mathrm{~h}$ from starting induction (Table 2) or the percentage of failure to reach $3 \mathrm{~cm}$ dilation $(9.1 \%$ in the misoprostol group and $13.8 \%$ in the dinoprostone group, $\mathrm{p}=$ $0.147)$.

The time from starting induction to vaginal birth was shorter for the dinoprostone-induced group (median of $20 \mathrm{~h}$ ) than for the vaginally misoprostolinduced group (median of $23.4 \mathrm{~h})(\mathrm{p}=0.018)$ (Table 2).

Parity is an important predictor factor for induced delivery, and also in its temporal evolution; $96.5 \%$ of the multipara and $80.2 \%$ of the nulliparous women had a vaginal birth; $38.7 \%$ of the nulliparous women and $79.5 \%$ of the multiparous had a vaginal birth in less than $24 \mathrm{~h}$ from starting induction $(\mathrm{p}<0.0001)$. For the nulliparous women, the time from starting induction to vaginal birth was also shorter for the vaginally dinoprostone-induced group (median of $21 \mathrm{~h}$ ) 
Table 2. Delivery outcomes.

\begin{tabular}{|c|c|c|c|c|c|}
\hline Outcomes & $\begin{array}{c}\text { Misoprostol } \\
\text { N (\%) }\end{array}$ & $\begin{array}{c}\text { Dinoprostone } \\
\text { N (\%) }\end{array}$ & $\mathrm{p}$ & $\mathbf{R R}$ & IC $95 \%$ \\
\hline Caesarean section & $34(14.1)$ & $31(19.4)$ & $0.161^{\star}$ & $1.38^{\star}$ & $0.89-2.13^{\times}$ \\
\hline Failed induction & $19(39.6)$ & $12(70.6)$ & 0.028 & 1.78 & $1.12-2.84$ \\
\hline \multicolumn{6}{|l|}{ Vaginal delivery $<24 \mathrm{~h}$} \\
\hline Total & $106(44)$ & $85(53.1)$ & 0.401 & $1.08^{*}$ & $0.90-1.29$ \\
\hline Nulliparas & $62(33.7)$ & $59(45.7)$ & 0.031 & 1.22 & $1.01-1.47$ \\
\hline Multiparas & $44(77.2)$ & $26(83.9)$ & 0.458 & 1.41 & $0.56-3.59$ \\
\hline \multicolumn{6}{|l|}{ Vaginal delivery $<12 \mathrm{~h}$} \\
\hline Total & $34(14.1)$ & $32(20)$ & 0.310 & $1.22^{*}$ & $0.82-1.81$ \\
\hline Nulliparas & $14(7.6)$ & $15(11.6)$ & 0.227 & 1.05 & $0.97-1.13$ \\
\hline Multiparas & $20(35.1)$ & $17(54.8)$ & 0.073 & 1.44 & $0.93-2.21$ \\
\hline Outcomes & $\begin{array}{c}\text { Misoprostol } \\
\text { Median (IQR) }\end{array}$ & $\begin{array}{l}\text { Dinoprostone } \\
\text { Median (IQR) }\end{array}$ & $\mathrm{p}$ & & \\
\hline \multicolumn{6}{|c|}{ Time to vaginal delivery $(h)$} \\
\hline Total & $23.4(17.1)$ & $20(17.3)$ & 0.018 & & \\
\hline Nulliparas & $26.7(15.5)$ & $21.1(15.9)$ & 0.004 & & \\
\hline Multiparas & $16.5(11.6)$ & $11(12.3)$ & 0.081 & & \\
\hline
\end{tabular}

*Adjusted in an explanatory logistic regression model.

Table 3. Maternal and fetal outcomes.

\begin{tabular}{cccccc}
\hline Outcomes & $\begin{array}{c}\text { Misoprostol } \\
\text { N (\%) }\end{array}$ & $\begin{array}{c}\text { Dinoprostone } \\
\text { N (\%) }\end{array}$ & p & RR & IC 95\% \\
Maternal outcomes & & & & & \\
Puerperal patology & $13(5.4)$ & $9(5.6)$ & 0.921 & 0.95 & $0.42-2.19$ \\
Intrapartum fever & $14(5.8)$ & $5(3.1)$ & 0.215 & 1.85 & $0.68-5.06$ \\
Uterine atony & $15(6.2)$ & $13(8.1)$ & 0.465 & 0.77 & $0.37-1.57$ \\
Fetal outcomes & & & & & \\
Neonatal weight (grams) & $3283(422)$ & $3133(489)$ & 0.002 & 150 & $57-243$ \\
pH < 7 & $2(0.9)$ & $2(1.3)$ & 1.000 & 0.67 & $0.09-4.69$ \\
1-min Apgar score <7 & $9(3.7)$ & $8(5)$ & 0.538 & 0.75 & $0.29-1.89$ \\
Need for neonatal resuscitation III-IV & $10(4.1)$ & $15(9.4)$ & 0.034 & 0.43 & $0.2-0.96$ \\
Neonatology admission & $16(6.6)$ & $18(11.3)$ & 0.142 & 0.59 & $0.31-1.12$ \\
\hline
\end{tabular}

*Data are presented as $\bar{X}(\mathrm{SD})$, mean differences.

than the vaginally misoprostol-induced one (median of $26.7 \mathrm{~h})(\mathrm{p}=0.004)$. No differences were found in the multipara group.

No differences were reported in maternal complications according to the cervical maturity method employed (Table 3).

No differences appeared in the $\mathrm{pH}$ value at birth, the Apgar score at 1 minute 
and 5 minutes, in having to be hospitalized in the Neonatology Unit, nor in the reasons for this hospitalization. However, the mean birth weight was $3133 \mathrm{~g}$ in the dinoprostone-induced group and $3283 \mathrm{~g}$ in the misoprostol-induced group. This difference was statistically significant $(\mathrm{p}=0.002)$ did not seem clinically relevant to us, but it was included for its adjustment in all the applied logistic regression models (Table 3 ).

The need for resuscitation types III and IV was greater for the neonates of the vaginally dinoprostone-induced group (9.4\%) than for those in the misoprostolinduced one $(4.1 \%), \mathrm{p}=0.034$. When we analyzed this difference, we found that the neonates who required neonatal resuscitation had a higher at-risk delivery, which was the reason for induction. The origin of the differences in neonatal resuscitation requirements lay in the reason for induction (pregnancy-related hypertension and meconium-stained amniotic fluid), which did not depend on the cervical maturity method employed (Table 3 ).

\section{Discussion}

As a result of the Spanish Agency of Medicines' approval in 2008 of misoprostol being vaginally administered in $25 \mathrm{mcg}$ tablets to induce at-term delivery, we began to opt for the low-dose misoprostol protocol and to substitute the gold standard which, in our setting and in many centres, still involves vaginally administering dinoprostone in its $10 \mathrm{mg}$ slow-releasing form. This change was the reason why we collected the data for the present work. However, the comparison made of these two methods, and with the present dose, has been poorly studied [4] [5] [6] [7] [8].

We carefully analyzed the 2010 Cochrane Database of Systematic Reviews (4). Only six of them compared misoprostol, at different doses, with $10 \mathrm{mg}$ dinoprostone in its slow-releasing form. Of these six, only the study by Wing (1997) compared dinoprostone and misoprostol at the $25 \mathrm{mcg} / 4 \mathrm{~h}$ dose; i.e., only one of the 121 included studies evaluated the exact dose employed in the present work [4] [8], which constitutes the "pharmacological change" taking place in Spanish delivery rooms.

The meta-analyses of Wang, Liu and Austin included 30 articles [5] [6] [7]. Only Wing, Bolnik and Harms used the same doses as we do for both drugs [8] [9] [10]. Of these three studies, that by Bolnik simultaneously employed misoprostol and dinoprostone, and intravenous oxytocin perfusion in different protocols. Thus, it is not comparable to the majority of studies, nor to our study, in which oxytocin was used after cervical maturity, and not concomitantly. Harms publication used our exact dose, but not exactly the same protocol for dinoprostone (maintained only for $12 \mathrm{~h}$ ). It is noteworthy that the data reported by Harms, presented in the Obstet Gynecol supplement, are limited by their poster condition in the ACOG's 50 ${ }^{\text {th }}$ Anniversary Meeting, held in 2001 [10]. The only publication with a similar dose and protocol to ours was that by Wing, which dates back to 1997, whose characteristics are like those presented herein. 
After making the logistic regression model adjustments, we found no differences in birth routes according to the cervical maturity method employed. The cesarean section rate was analyzed in all the studies and meta-analyses. The results reported by the various authors coincided with our results, although they obtained a higher cesarean section rate than we did [4] [5] [6] [7] [8].

We obtained a lower cesarean section rate due to failed induction in the misoprostol group, although these data in all the works published to date are contradictory. Works like those of Chitrakar or Belfrage also obtained a lower failed induction percentage for the misoprostol group. However, they identified higher misoprostol doses than the dose we used [11] [12]. In others, like Wing's series, at our dose they found no inter-group differences for the reason for performing cesarean section [8]. We should point out that the time to consider an induction failed is currently a matter of debate. Therefore, the results may not measure exactly the same variable, which maybe the true reason for the difference [13].

We observed a difference in the statistical significance limit for the mean Bishop score obtained at the end of cervical maturity, with more favorable necks of the womb in the misoprostol-induced group. This coincides with the few data published on this matter (Chitrakar and Saxena), but are not comparable, however, to our data given the different protocols and doses employed [11] [14]. The work by Wing does not offer this information [8].

Former works have associated induction with misoprostol with higher meconium fluid rates and greater oxytocin requirements [4] [5] [6] [7]. Both variables were homogeneously distributed between our two study groups. Wing, who used our same dose, published comparable results to ours [8]. It is quite likely that this discrepancy lies in the different doses used for both drugs.

We obtained no differences in the percentage of "vaginal birth in less than 24 $h$ " and "in less than $12 \mathrm{~h}$ " from the start of induction between our groups. Previously studies have either found no differences for this variable or, if they did, they conferred a temporal advantage to misoprostol [5] [4] [6] [7]. Nevertheless, we thought it was worth analyzing these data in detail. Liu, who reported a higher vaginal birth percentage in $<24 \mathrm{~h}$ for the misoprostol group, did not include any work that used our same dose for both drugs [6]. It is worth highlighting that Austin informed about a significant heterogeneity for the variables "accomplishing vaginal birth in less than $24 \mathrm{~h}$ " and "in less than $12 \mathrm{~h}$ ", justified given the differences in design, the Bishop score at the start of induction, duration of dinoprostone exposure, misoprostol dose and the oxytocin administration protocol [7]. After running a random effects model, no differences were found when ruling out some works included in the meta-analysis, with two exceptions: when ignoring the studies of Wing and Bolnik, the rate of "accomplishing vaginal birth in less than $12 \mathrm{~h}$ " rose for the misoprostol group [8] [9]; removing both these studies in this meta-analysis meant eliminating all the works in which misoprostol was used at the $25 \mathrm{mcg} / 4 \mathrm{~h}$ dose as opposed to $10 \mathrm{mg}$ dinoprostone administered vaginally; i.e., when the works that reported using 
high misoprostol doses were left in the meta-analysis ( $\geq 50 \mathrm{mg} / 4-6 \mathrm{~h}$ ), the efficacy of this drug increased. So, although some former analyses confer a temporal advantage to misoprostol, it might be a dose-dependent and not a drug-dependent result.

The time between induction starting and vaginal birth was shorter for the dinoprostone group. Wing, who used the same doses as we did, found no differences in this variable. Other works have conferred a temporal advantage to misoprostol [4] [6]. Once again, the employed dose was not comparable to ours, so we thought that dose could be behind this discrepancy. Nonetheless, our results are limited and further studies to allow us to draw definite conclusions are needed.

Regarding safety, our work thoroughly analyzed maternal-fetal complications, but found no differences due to the cervical maturity method employed.

Of all the births included, puerperium was normal in $94.5 \%$ and presented some pathology in 5.5\% (fever, uterine atony, headache, need for blood transfusion or curettage), with no differences according to the cervical maturity method employed. The present series included no uterine rupture.

Data on puerperal complications in the literature are extremely scarce. Most series inform in detail about neonatal data and the sporadic presence of some serious, but infrequent complication, such as uterine rupture. However, all the metaanalyses concluded that the studies were not large enough to evaluate such infrequent and serious maternal-fetal complications [4] [5] [6] [7]. We think it is necessary to insist on the importance of reporting possible associated complications in detail.

Our main limitation was to not report data on abnormal uterine activity and its consequences on fetal cardiotocographic records. We cannot ignore its importance when evaluating the safety profile of the prostaglandins employed. Wing reported low tachysystole rates (defined as six contractions or more in 10 minutes on at least a 20-minute monitoring window) for the group induced with misoprostol, and no differences for uterine hyperstimulation [8]. Harms indicated no differences [10]. Thus, more works are necessary to evaluate the frequency of alterations in uterine contractions at the doses employed under study.

After the analysis, we found discrepancies between the neonatal resuscitation requirements in our work behind the reason for induction, which did not depend on the cervical maturity method used. Other former works that have indicated this information found no differences [8] [15] [16].

Our main limitation is the non-randomized study design. Notwithstanding, after applying the logistic regression models needed to adjust the confounder and interaction variables, we believe that the present study shows that our study groups are comparable and homogeneous, and our results are sound.

\section{Conclusions}

We found no discrepancy in our series as to the cesarean section rate between 
labor induction with misoprostol administered vaginally in its low-dose protocol ( $25 \mathrm{mcg} / 4-6 \mathrm{~h}$, for $24 \mathrm{~h}$ at the most) with vaginal dinoprostone induction using $10 \mathrm{mg}$ in its slow-releasing form (for $24 \mathrm{~h}$ at the most).

No differences were found in the percentage of pregnant women who underwent vaginal birth in less than $24 \mathrm{~h}$ and less than $12 \mathrm{~h}$ since induction began, nor in the maternal-neonatal results according to the cervical maturity method used after adjusting for the confounder variables.

Given the pharmacological change taking place in Spanish delivery rooms and the few studies that compare the exact dose and posology used herein, we believe that it is necessary to perform clinical assays to compare misoprostol and dinoprostone at the doses employed herein, and to include the results that relate to induced pregnant women's satisfaction.

\section{References}

[1] Sociedad Española de Ginecología y Obstetricia (2013) Protocolo de Inducción de Parto de la SEGO. http://www.prosego.com

[2] Michelle, J.K., Osterman, M.J., et al. (2014) Recent Declines in Induction of Labor by Gestational Age. NCHS Data Briefs, No. 155, 1-8.

[3] ACOG Committee on Practice Bulletins-Obstetrics (2009) Induction of Labor.

[4] Hofmeyr, G.J., Gülmezoglu, A.M. and Pileggi, C. (2010) Vaginal Misoprostol for Cervical Ripening and Induction of Labour. Cochrane Database of Systematic Reviews, 6, CD000941. https://doi.org/10.1002/14651858.CD000941.pub2

[5] Wang, L., Zheng, J., Wang, W., Fu, J. and Hou, L. (2015) Efficacy and Safety of Misoprostol Compared with the Dinoprostone for Labor Induction at Term: A MetaAnalysis. The Journal of Maternal-Fetal \& Neonatal Medicine, 22, 1-11. https://doi.org/10.3109/14767058.2015.1086331

[6] Liu, A., Lv, J., Hu, Y., Lang, J., et al. (2014) Efficacy and Safety of Intravaginal Misoprostol versus Intracervical Dinoprostone for Labor Induction at Term: A Systematic Review and Meta-Analysis. Journal of Obstetrics and Gynaecology Research, 40, 897-906. https://doi.org/10.1111/jog.12333

[7] Austin, S.C., Sanchez-Ramos, L. and Adair, C.D. (2010) Labor Induction with Intravaginal Misoprostol Compared with the Dinoprostone Vaginal Insert: A Systematic Review and Metaanalysis. American Journal of Obstetrics \& Gynecology, 202,624

[8] Wing, D.A., Ortiz-Omphroy, G. and Paul, R.H. (1997) A Comparison of Intermittent Vaginal Administration of Misoprostol with Continuous Dinoprostone for Cervical Ripening and Labor Induction. American Journal of Obstetrics \& Gynecology, 177, 612-618.

[9] Bolnik, J.M., et al. (2004) Randomized Trial between Two Active Labor Management Protocols in the Presence of an Unfavorable Cervix. American Journal of $\mathrm{Ob}$ stetrics \& Gynecology, 190, 124-128.

[10] Harms, K., Nguyen, C., Toy, E.C. and Baker, B. (2001) Intravaginal Misoprostol versus Cervidil for Cervical Ripening in Term Pregnancies. Obstetrics \& Gynecology, 97, S36. https://doi.org/10.1097/00006250-200104001-00086

[11] Chitrakar, N.S. (2012) Comparison of Misoprostol versus Dinoprostone for PreInduction Cervical Ripening At-Term. Journal of Nepal Health Research Council, 10, 10-15. 
[12] Belfrage, P., Smedyviq, E., Gjessing, L., et al. (2000) A Randomized Prospective Study of Misoprostol and Dinoproston for Induction of Labor. Acta Obstetricia et Gynecologica Scandinavica, 79, 1065-1068.

[13] Spong, C.Y., Berghella, V., Wenstrom, K.D., et al. (2012) Preventing the First Cesarean Delivery: Summary of a Joint Eunice Kennedy Shriver National Institute of Child Health and Human Development, Society for Maternal-Fetal Medicine, and American Colleague of Obstetricians and Gynecologists Workshop. Obstetrics \& Gynecology, 120, 1181-1193.

[14] Saxena, P., Puri, M., Bajaj, M., et al. (2011) A Randomized Control Trials to Compare the Efficacy of Different Doses of Intravaginal Misoprostol with Intracervical Dinoprostone for Cervical Ripening and Labor Induction. European Review for Medical and Pharmacological Sciences, 15, 759-763.

[15] Ozkan, S., Caliskan, E., Doger, E., et al. (2009) Comparative Efficacy of Vaginal Misoprostol versus Dinoprostone Vaginal Insert in Labor Induction at Term: A Randomized Trial. Archives of Gynecology and Obstetrics, 280, 19-24. https://doi.org/10.1007/s00404-008-0843-9

[16] Ayaz, A., Shaukat, S., Farook, M.U., et al. (2010) Induction of Labor: A Comparative Study of Intravaginal Misoprostol and Dinoprostone. Taiwanese Journal of Obstetrics and Gynecology, 49, 151-155.

\section{Scientific Research Publishing}

\section{Submit or recommend next manuscript to SCIRP and we will provide best} service for you:

Accepting pre-submission inquiries through Email, Facebook, LinkedIn, Twitter, etc. A wide selection of journals (inclusive of 9 subjects, more than 200 journals)

Providing 24-hour high-quality service

User-friendly online submission system

Fair and swift peer-review system

Efficient typesetting and proofreading procedure

Display of the result of downloads and visits, as well as the number of cited articles

Maximum dissemination of your research work

Submit your manuscript at: http://papersubmission.scirp.org/

Or contact ojog@scirp.org 